\title{
Methods and Concepts for Designing and Validating Smart Grid Systems
}

\author{
Thomas I. Strasser ${ }^{1, *}\left(\mathbb{D}\right.$, Sebastian Rohjans ${ }^{2, *}$ and Graeme M. Burt ${ }^{3, *}$ (i) \\ 1 Electric Energy Systems, Center for Energy, AIT Austrian Institute of Technology, 1210 Vienna, Austria \\ 2 Department of Information and Electrical Engineering, Hamburg University of Applied Sciences, \\ 20099 Hamburg, Germany \\ 3 Institute for Energy and Environment, Electronic and Electrical Engineering Department, University of \\ Strathclyde, Glasgow G1 1XW, UK \\ * Correspondence: thomas.strasser@ait.ac.at (T.I.S.); sebastian.rohjans@haw-hamburg.de (S.R.); \\ graeme.burt@strath.ac.uk (G.M.B.); Tel.: +43-664-2351934 (T.I.S.)
}

Received: 1 March 2019; Accepted: 13 May 2019; Published: 15 May 2019

check for updates

\begin{abstract}
This Editorial provides an introduction to the Special Issue "Methods and Concepts for Designing and Validating Smart Grid Systems". Furthermore, it also provides an overview of the corresponding papers that where recently published in MDPI's Energies journal. The Special Issue took place in 2018 and accepted a total of 19 papers from 19 different countries.
\end{abstract}

Keywords: design, development and implementation methods for smart grid technologies; modelling and simulation of smart grid systems; co-simulation-based assessment methods; validation techniques for innovative smart grid solutions; real-time simulation and hardware-in-the-loop experiments

\section{Introduction}

Energy efficiency and low-carbon technologies are key contributors to curtailing the emission of green-house gases that continue to cause global warming. The efforts to reduce green-house gas emissions also strongly affect electrical power systems. Renewable sources, energy storage systems and flexible loads provide new system controls, but power system operators and utilities have to deal with their fluctuating nature, limited storage capabilities and typically higher infrastructure complexity with a growing number of heterogeneous components. In addition to the technological change of new components, the liberalisation of energy markets and new regulatory rules bring contextual change that necessitates the restructuring of the design and operation of future energy systems. Sophisticated component design methods, intelligent information and communication architectures, automation and control concepts, new and advanced markets, as well as proper standards are necessary in order to manage the higher complexity of such intelligent power systems that form the smart grid.

Due to the considerably higher complexity of such cyber-physical energy systems (CPES), constituting power system, automation, protection, information and communication technology (ICT), as well as system services, it is expected that the design and validation of smart grid configurations will play a major role in future technology and system developments. However, an integrated approach for the design and evaluation of smart grid configurations incorporating these diverse constituent parts remains evasive. Validation approaches available today focus mainly on component-oriented methods. In order to guarantee a sustainable, affordable and secure supply of electricity through the transition to a future smart grid with considerably higher complexity and innovation, new design, validation and testing methods appropriate for CPES is required. Papers that present results related to the design and validation of smart grid systems have been targeted by this Special Issue. 


\section{Content of the Special Issue}

The accepted and published papers address a wide range of challenging and interesting methods and concepts in the domain of designing and validating smart grid systems, which can be mainly grouped into six clusters related to the following:

(1) System design methods;

(2) Simulation concepts;

(3) Co-simulation approaches;

(4) Hardware-in-the-loop (HIL) experiments;

(5) Laboratory tests; and

(6) Optimisation techniques.

Table 1 provides a brief overview of the assignment of the papers to the aforementioned clusters.

Table 1. Topics and included papers of the Special Issue.

\begin{tabular}{cc}
\hline Topic & References \\
\hline System design methods & {$[1-3]$} \\
Simulation concepts & {$[4-7]$} \\
Co-simulation approaches & {$[8,9]$} \\
Hardware-in-the-Loop experiments & {$[10-14]$} \\
Laboratory tests & {$[15,16]$} \\
Optimisation techniques & {$[17-19]$} \\
\hline
\end{tabular}

\subsection{System Design Methods}

Often, the development of new approaches and methods begins with the design of the target system. This forms the basis for the implementation, which in turn can be evaluated in various ways.

For example, in [1], a market design was developed that addresses system balancing products within a web-of-cells (WoC) architecture. The focus is on a solution that is as economically efficient as possible. Based on a literature search, as well as analysis methods, different possibilities were compared. In contrast, the authors in [2] explored ways to transfer approaches from other domains, such as healthcare, to the domain of smart grids. In particular, within the framework of the project "Integration of the Energy System" (IES), Austria, interoperable communication will be the focus of attention. An essential element of this is a standard from the International Electrotechnical Commission (IEC), namely IEC 61850. A third approach to architectural modelling is the smart grid architecture model (SGAM) [3]. The SGAM, which provides a structured basis for the design, development and validation of new solutions and technologies, will be analysed in terms of its past use in Europe and its adaptations to other domains.

\subsection{Simulation Concepts}

A first and early approach to evaluate new concepts is simulation. With simple models, quick first insights can be gained, which can lead to the successive improvement of the solution. Simulations can be used in many different ways.

In [4], simulation was used to analyse a four-cell reference power system to evaluate a new controller. This controller follows a new strategy for dynamically adjusting the power frequency characteristic based on the imbalance state. The authors in [5] were able to demonstrate through simulations that their proposed effective filtering approach (EFA), to improve network traffic performance for the high-availability seamless redundancy (HSR) protocol, reduces network unicast traffic by up to $80 \%$. Simulation of an unbalanced $12.47-\mathrm{kV}$ feeder with 12,780 households and 1000 electric vehicles (EV) under peak and auxiliary load conditions was conducted in [6] to analyse a 
three-phase loss allocation procedure for distribution networks. The authors in [7] in turn simulated a well-known IEEE 14 bus test system for analysing a developed data mining algorithm. The data came from phasor measurement units (PMU), and the algorithm pursued the goal of better integration of wind turbines.

\subsection{Co-Simulation Approaches}

In some cases, it is not possible to determine in advance how the environment will look for a new solution. This also implies that it is not clear which factors influence a new solution. This is where the co-simulation approach has become established. Different simulation environments and models are coupled in order to map complex overall system scenarios.

Since the term co-simulation can be a broad field that takes very different depths of detail into account, the authors in [8] devoted themselves to a systematic structuring of different approaches. The authors in [9] used a specific co-simulation platform to demonstrate that the public mobile telecommunication system 4G long-term evolution (LTE) is applicable for fault location, isolation and system restoration (FLISR) applications in radially- and weakly-meshed medium voltage distribution networks.

\subsection{Hardware-in-the-Loop Experiments}

However, in comparison to co-simulation, if the deployment environment of a new solution, such as that of a controller, can be clearly defined, HIL-based tests are an obvious choice. Here, the real environment of the controller is simulated, and its behaviour is evaluated.

In the field of energy supply, a specific form of HIL, power hardware-in-the-loop (PHIL), has become established. Since the interface between the virtual part (simulated environment) and the real part (for example, the controller) is of the highest importance here, so far, many interface algorithms (IA) have been developed. The authors in [10] examined which IA were suitable for which PHIL experiments. In [14], two concrete approaches-a conventional PHIL design and a simplified structure based on a quasi-dynamic PHIL approach-were compared. Another important aspect of PHIL experiments is that the simulated system or its behaviour may be heavily dependent on whether the hardware being tested is connected. In particular, the initialisation of a real-time simulator (RTS) can lead to problems here. This problem was addressed by the authors in [12] by introducing a procedure for initialising PHIL simulations for synchronous power systems. Another field of application for PHIL is microgrids or their control; in particular, distributed concepts, e.g., through the implementation of multi-agent systems, and experiments are offered for PHIL in [13]. The simulation of PMU has already been mentioned, and distribution phasor measurement units (D-PMU) and micro-synchrophasors (micro-PMUs) are also addressed in [11]. Specifically, the authors presented a vendor-agnostic PMU real-time simulation and HIL (PMU-RTS-HIL) approach.

\subsection{Laboratory Tests}

The methods described so far for the validation of new approaches are characterised by a predominant use of software. Solutions that have a higher degree of maturity are then validated in lab-based tests before being field-integrated into real systems.

The authors in [15] dealt again with microgrids. They investigated whether distributed voltage control systems can be a serious alternative to centralised approaches. For this purpose, the development, the structure and the operation of a corresponding hardware-based lab test stand was described. In a further laboratory setup, the behaviour of active distribution networks was analysed, which were strongly penetrated by renewable energies [16]. This was examined by means of various parameters (tap changers of the transformers in the primary substation, reactive power injections of the renewable energy sources and active and reactive power exchanged between adjacent feeders being interconnected through a direct current link), to show what an optimal control can look like. 


\subsection{Optimisation Techniques}

In addition to the development of new solutions, a significant part of research and development in smart grid systems is also concerned with the optimisation of existing approaches and methods. However, these optimisations can only be performed if the system was fully understood in advance. This in turn implies extensive prior validations.

The authors in [17] dealt with an optimisation of the coordination of reserve allocations in multiple-cell-based power systems. The starting point was the implementation of linear decision rule (LDR)-based guidelines. An energy market-based optimisation was pursued by the authors in [18]. The intended goal was to offer flexibility bids for a real-time balancing market. Finally, in [19], the concept of microgrids was focused on again. The authors investigated how microgrids prevent weather-related network outages by creating more robust structures. The result was an optimised power supply.

\section{Conclusions and Outlook}

All 19 papers (17 articles and two reviews) described exciting new design, validation and testing methods for CPES. Several of them were done in the context of funded research and development projects, especially with support from the European Union framework programmes. They covered approaches from system design to (co-)simulation and HIL, to laboratory tests and optimisation. With those methods in hand, the validation on system level becomes possible. However, future research and technology development are still necessary in order to further develop those approaches, to harmonise them and to provide corresponding frameworks and tools.

Acknowledgments: The guest Editors would like to thank the authors for submitting their excellent contributions to this Special Issue. Furthermore, they would like to express their sincerest gratitude to Energies' in-house Editor and reviewers for their wonderful work and effort. Without their support, the efficient handling of all received manuscripts (article average processing time was 40.48 days), it would not have been possible to publish this Special Issue. Moreover, this Editorial has been supported through the European Community's Seventh Framework Program (FP7/2007-2013) under Project "ELECTRA IRP" (Grant Agreement No. 609687), as well as by the European Community's Horizon 2020 Program (H2020/2014-2020) under Project "ERIGrid"(Grant Agreement No. 654113).

Conflicts of Interest: The authors declare no conflict of interest.

\section{Abbreviations}

$\begin{array}{ll}\text { CPES } & \text { Cyber-physical energy system } \\ \text { D-PMU } & \text { Distribution phasor measurement unit } \\ \text { EFA } & \text { Effective filtering approach } \\ \text { EV } & \text { Electric vehicle } \\ \text { FLISR } & \text { Fault location, isolation and system restoration } \\ \text { HIL } & \text { Hardware-in-the-loop } \\ \text { HSR } & \text { High-availability seamless redundancy } \\ \text { IA } & \text { Interface algorithms } \\ \text { ICT } & \text { Information and communication technology } \\ \text { IEC } & \text { International Electrotechnical Commission } \\ \text { IEEE } & \text { Institute of Electrical and Electronics Engineers } \\ \text { IES } & \text { Integrating the energy system } \\ \text { LDR } & \text { Linear decision rules } \\ \text { LTE } & \text { Long-term evolution } \\ \text { Micro-PMU } & \text { Micro-synchrophasor } \\ \text { PHIL } & \text { Power hardware-in-the-loop } \\ \text { PMU } & \text { Phasor measurement unit } \\ \text { RTS } & \text { Real-time simulator } \\ \text { SGAM } & \text { Smart grid architecture model } \\ \text { WoC } & \text { Web-of-cells }\end{array}$




\section{References}

1. Bobinaite, V.; Obushevs, A.; Oleinikova, I.; Morch, A. Economically Efficient Design of Market for System Services under the Web-of-Cells Architecture. Energies 2018, 11. [CrossRef]

2. Gottschalk, M.; Franzl, G.; Frohner, M.; Pasteka, R.; Uslar, M. From Integration Profiles to Interoperability Testing for Smart Energy Systems at Connectathon Energy. Energies 2018, 11. [CrossRef]

3. Uslar, M.; Rohjans, S.; Neureiter, C.; Pröstl Andrén, F.; Velasquez, J.; Steinbrink, C.; Efthymiou, V.; Migliavacca, G.; Horsmanheimo, S.; Brunner, H.; et al. Applying the Smart Grid Architecture Model for Designing and Validating System-of-Systems in the Power and Energy Domain: A European Perspective. Energies 2019, 12. [CrossRef]

4. Rikos, E.; Caerts, C.; Cabiati, M.; Syed, M.; Burt, G. Adaptive Fuzzy Control for Power-Frequency Characteristic Regulation in High-RES Power Systems. Energies 2017, 10. [CrossRef]

5. Tien, N.X.; Rhee, J.M.; Park, S.Y. A Combined Approach Effectively Enhancing Traffic Performance for HSR Protocol in Smart Grids. Energies 2017, 10. [CrossRef]

6. De Oliveira-De Jesus, P.M.; Rios, M.A.; Ramos, G.A. Energy Loss Allocation in Smart Distribution Systems with Electric Vehicle Integration. Energies 2018, 11. [CrossRef]

7. Klarić, M.; Kuzle, I.; Holjevac, N. Wind Power Monitoring and Control Based on Synchrophasor Measurement Data Mining. Energies 2018, 11. [CrossRef]

8. Nguyen, V.H.; Besanger, Y.; Tran, Q.T.; Nguyen, T.L. On Conceptual Structuration and Coupling Methods of Co-Simulation Frameworks in Cyber-Physical Energy System Validation. Energies 2017, 10. [CrossRef]

9. Garau, M.; Ghiani, E.; Celli, G.; Pilo, F.; Corti, S. Co-Simulation of Smart Distribution Network Fault Management and Reconfiguration with LTE Communication. Energies 2018, 11. [CrossRef]

10. Brandl, R. Operational Range of Several Interface Algorithms for Different Power Hardware-In-The-Loop Setups. Energies 2017, 10. [CrossRef]

11. Stifter, M.; Cordova, J.; Kazmi, J.; Arghandeh, R. Real-Time Simulation and Hardware-in-the-Loop Testbed for Distribution Synchrophasor Applications. Energies 2018, 11. [CrossRef]

12. Guillo-Sansano, E.; Syed, M.H.; Roscoe, A.J.; Burt, G.M. Initialization and Synchronization of Power HardwareIn-The-Loop Simulations: A Great Britain Network Case Study. Energies 2018, 11. [CrossRef]

13. Nguyen, T.L.; Guillo-Sansano, E.; Syed, M.H.; Nguyen, V.H.; Blair, S.M.; Reguera, L.; Tran, Q.T.; Caire, R.; Burt, G.M.; Gavriluta, C.; et al. Multi-Agent System with Plug and Play Feature for Distributed Secondary Control in Microgrid-Controller and Power Hardware-in-the-Loop Implementation. Energies 2018, 11. [CrossRef]

14. Ebe, F.; Idlbi, B.; Stakic, D.E.; Chen, S.; Kondzialka, C.; Casel, M.; Heilscher, G.; Seitl, C.; Bründlinger, R.; Strasser, T.I. Comparison of Power Hardware-in-the-Loop Approaches for the Testing of Smart Grid Controls. Energies 2018, 11. [CrossRef]

15. Almasalma, H.; Claeys, S.; Mikhaylov, K.; Haapola, J.; Pouttu, A.; Deconinck, G. Experimental Validation of Peer-to-Peer Distributed Voltage Control System. Energies 2018, 11. [CrossRef]

16. García-López, F.D.P.; Barragán-Villarejo, M.; Marano-Marcolini, A.; Maza-Ortega, J.M.; Martínez-Ramos, J.L. Experimental Assessment of a Centralised Controller for High-RES Active Distribution Networks. Energies 2018, 11. [CrossRef]

17. Hu, J.; Lan, T.; Heussen, K.; Marinelli, M.; Prostejovsky, A.; Lei, X. Robust Allocation of Reserve Policies for a Multiple-Cell Based Power System. Energies 2018, 11. [CrossRef]

18. Camargo, J.; Spiessens, F.; Hermans, C. A Network Flow Model for Price-Responsive Control of Deferrable Load Profiles. Energies 2018, 11. [CrossRef]

19. Uski, S.; Forssén, K.; Shemeikka, J. Sensitivity Assessment of Microgrid Investment Options to Guarantee Reliability of Power Supply in Rural Networks as an Alternative to Underground Cabling. Energies 2018, 11. [CrossRef]

(C) 2019 by the authors. Licensee MDPI, Basel, Switzerland. This article is an open access article distributed under the terms and conditions of the Creative Commons Attribution (CC BY) license (http:/ / creativecommons.org/licenses/by/4.0/). 